\title{
Familial glaucoma
}

\section{In nine generations of a South Hampshire family}

\author{
J. P. MARTIN AND E. G. ZORAB \\ Southampton Eye Hospital
}

A. Zorab (1932) reported a family suffering from "glaucoma simplex familialis" over three generations, the inheritance being autosomal dominant. Over the last 40 years, the variousir branches of this family have increased in number and two further generations have been ${ }_{\mathcal{E}}^{j}$ added. In addition, four affected generations before those reported by A. Zorab (which he did not know about) have now been discovered. The purpose of this paper is to report the full extent of the pedigree of this family as far as is now known, and to describe the mani- 3 festations of this particular familial chronic glaucoma and the way in which the disease progresses and responds to treatment. The glaucoma is associated with an abnormally $\overrightarrow{0}$ developed iris and angle, but behaves rather like chronic simple glaucoma.

\section{Material and methods}

The known family now consists of nine generations with 62 members (Fig. I). Of these, $29(47 \%) \stackrel{๊}{\circ}$ are affected with chronic glaucoma. Although the family is Scots in origin, most of the members nowe live in South Hampshire. Most of them, whether affected or not, have been examined by one of us $\vec{O}$ at some time; they are numbered on the pedigree (Fig. I). Those who are affected are under the

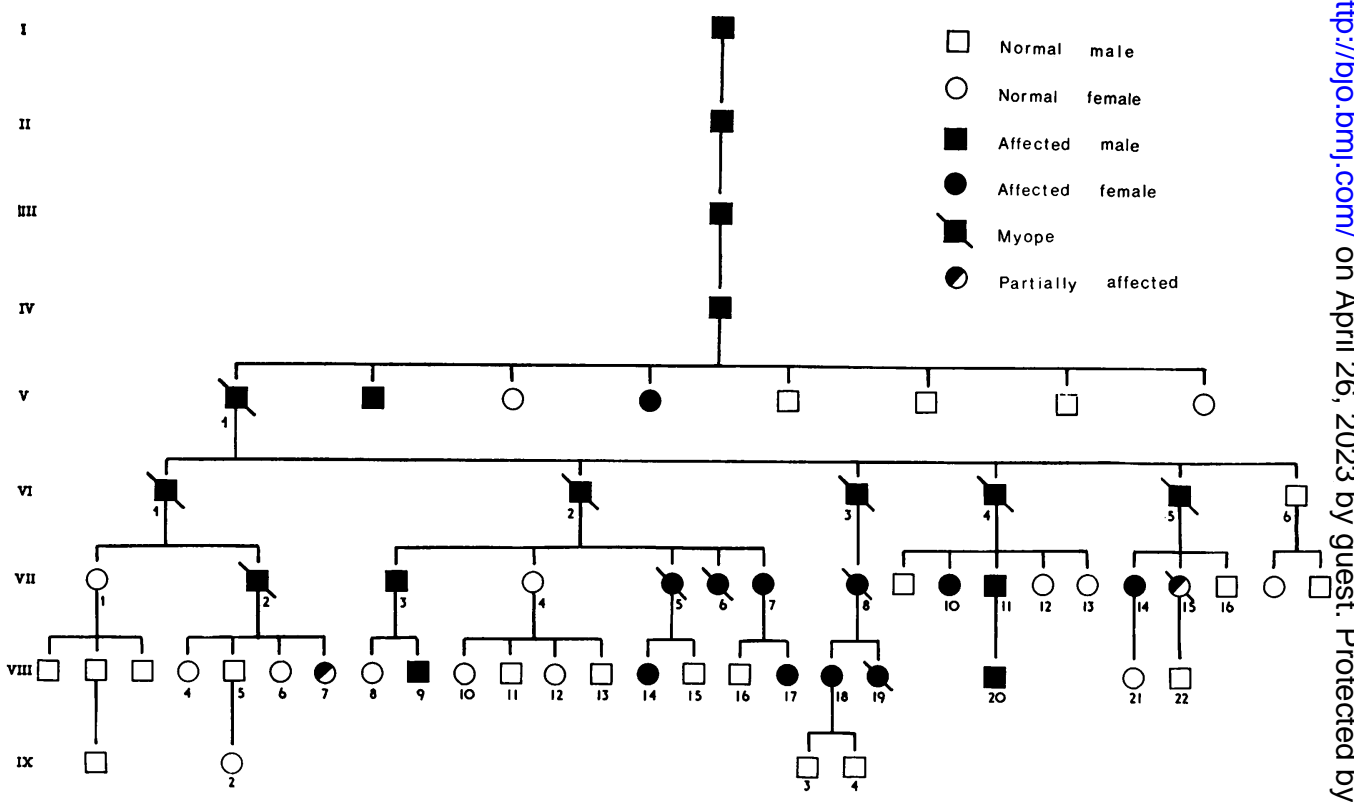

FIG. I Present family pedigree. The members which are numbered have been examined by the authors

Address for reprints: J. P. Martin, F.R.C.S., Ed., Royal Eye Infirmary, Plymouth, Devon. 


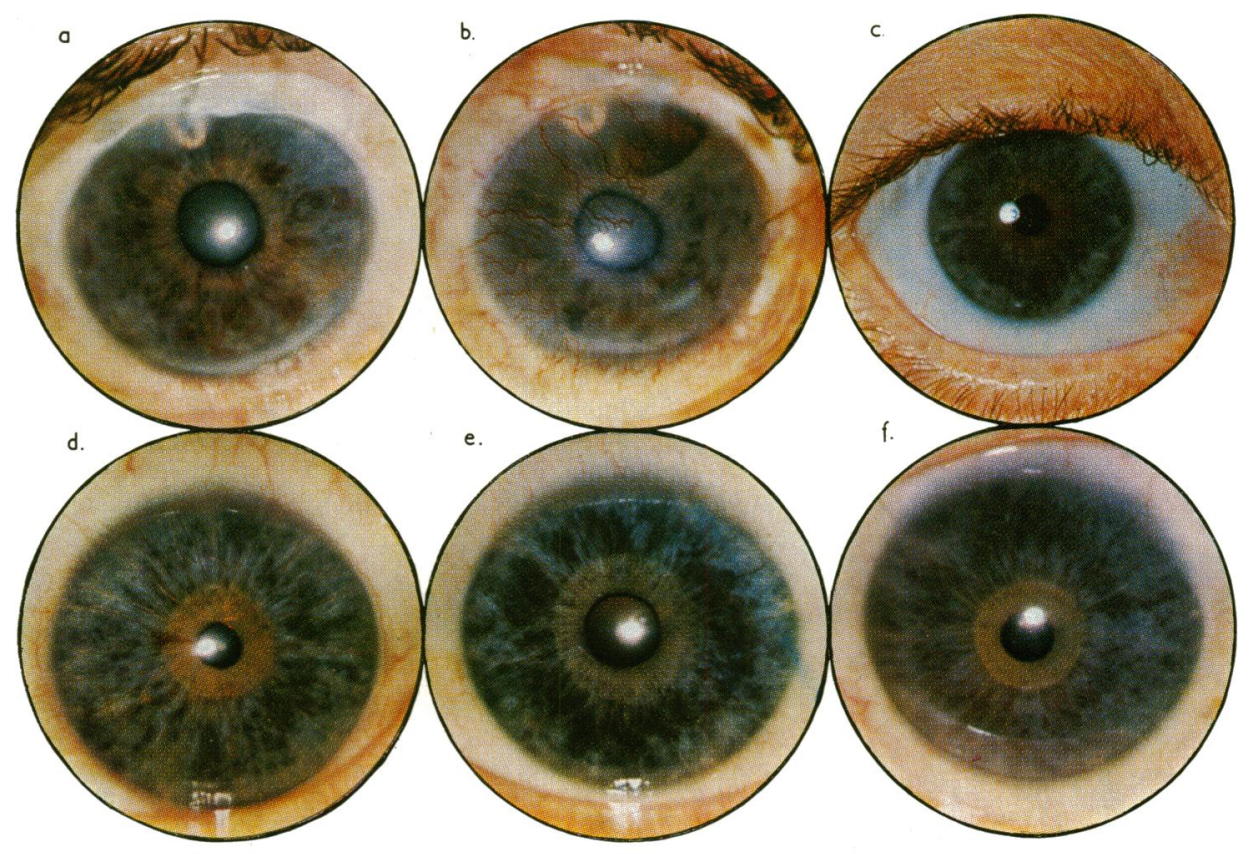

9

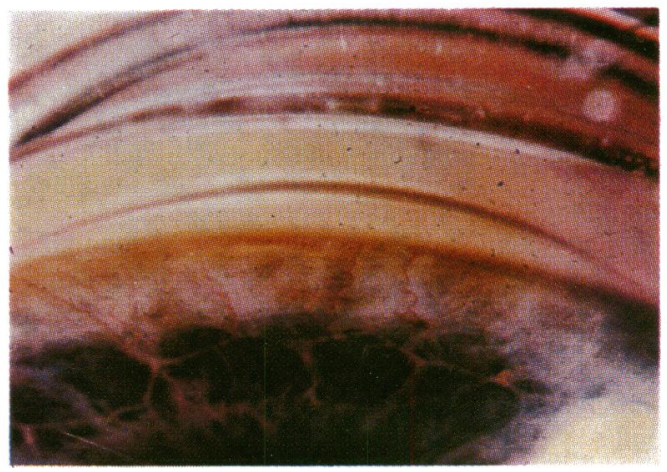

FIG. 2 (a) VI 5 Right eye: has had aqueoplasty operation

(b) VI 5 Left eye: has had aqueoplasty operation; cornea now becoming vascularized

(c) VII 6 Right eye: showing iris colour and structure typical of affected members

(d) VII 6 Left eye: showing iris colour and structure typical of affected members

(e) VII 7 Right eye: showing iris colour and structure typical of affected members

$(f)$ VII I I Left eye: showing iris colour and structure typical of affected members

(g) Gonioscopic view, showing sheet of mesodermal tissue on iris surface spreading from angle towards pupil; abnormal radial iris vessels can also be seen. 
care of one of us (E.C.Z.) at Southampton Eye Hospital. The members of the first four generations have not been examined since they are now dead. However, there is a strong and definite family history suggesting that each was affected and became blind in middle life. One branch of the family now living has moved to the north of England (Generation VII I); we have not examined these members but they are believed not to be affected.

Our findings and the description of the clinical features are based on the examination of those affected and non-affected members of the family that we have seen over the past 25 years. All affected patients are still under regular supervision. We do not propose to describe each patient separately, but rather to give a general account of this particular form of familial chronic glaucoma.

\section{Clinical features}

The most striking feature about the affected members of the family is the colour of the irides. The first generation-a Scot-(who must have been alive at the time of Culloden Moor) was known as "Ian of the Blackberry Eyes." This is an apt description, for the irides are a dark slate-grey colour all over. It is so striking that one can say at a glance whether or not a particular member of the family has glaucoma or will be affected by glaucoma. Apart from the distinctive colour, the iris lacks the usual stromal pattern all over and has a smooth appearance; also, the iris crypts are absent. The pupil is central and circular. In two patients the iris is only partially affected: in one (VIII 7) each iris is half normal and half of the affected type, and in the other (VII I5) the iris shows the usual lack of stromal pattern, but the colour is more brown and less grey than is usual in the affected members of this family.

Slit-lamp examination of the iris reveals radial vessels on the anterior surface in most cases; these run from a circular vessel in the angle towards the pupillary margin. Several vessels, varying from four to about ten, may be seen.

All members of the family who have developed glaucoma have this peculiar colour and structure of the iris, and glaucoma has not been found in any member without this peculiarity. It is, therefore, well recognized by this family as a marker for probable glaucoma. If the irides of the young children of the family are normal when they are examined in the clinic for the first time, they are pronounced unaffected, and will not develop glaucoma. These children are not seen again. Those affected are kept under observation.

Gonioscopy reveals that most angles are basically open all round, with excessive mesodermal tissue obliterating the features of the trabecular meshwork. The amount of mesodermal tissue is variable, sometimes sparse, sometimes considerable, and in some patients it appears as clumps. This tissue appears to spread like a smooth sheet from the cornea (Schwalbe's ring) round the angle onto the iris, passing towards the pupil. There may be peripheral anterior synechiae. A typical feature is a circumferential vessel found in the angle; this may run all the way round the angle, or may be broken up into sectors; in a few cases it is not present. This vessel may be doubled in some part of the angle; it then joins to continue as a single vessel. Radial vessels can be seen arising from the circumferential vessel and they pass forwards towards the pupil. In some cases they are surrounded by, or appear to arise from, a mount or digitation of mesodermal tissue, which passes from the angle towards the pupil. Some affected members of the family have narrow angles (Fig. 2).

The intraocular pressure in these patients has been measured by applanation tonometry over the last I I years; previously it was measured with a Schiötz tonometer. In a normal patient $2 \mathrm{I} \mathrm{mm}$.Hg is accepted as the upper limit of the normal range. In this family we have come to accept a higher figure as being reasonable in younger patients, i.e. $25^{-26}$ 
mm.Hg. Up to this pressure the optic discs appear to retain their normal features; no field loss occurs and over the years these eyes appear to be able to withstand a higher pressure than the normal eye. Patients with pressures of $26 \mathrm{~mm} . \mathrm{Hg}$ or more are treated. The various affected children of the family have their applanation tensions measured as soon as they are able to co-operate, i.e. at about 6 to 8 years. Although the intraocular pressure may remain at a fairly constant level in most affected members of the family, intermittent episodes of raised pressure occur in some of them. These last for a few hours or a few days, $\stackrel{\mathbb{D}}{\circ}$ and are associated with some visual impairment, pain, corneal oedema, and an introcular in pressure considerably above the previously recorded levels. These episodes are not due to $\vec{\circ}$ angle closure. They respond to energetic treatment and the eye can be restored to its former regime of therapy in a few weeks.

Tonography has been performed in a number of affected patients. These values were significant in some cases; in six patients the results of the corrected coefficient of aqueous 0 outflow (c) was from 0.05 to $0 \cdot 19$. The value of $P_{0} / \mathrm{C}$ was usually significant and varied from 94-400 (Table I).

Table I Results of tonography in affected members

\begin{tabular}{|c|c|c|c|}
\hline Member & Eye & $\begin{array}{l}\text { Coefficient of aqueous outflow } \\
\text { (corrected) } c\end{array}$ & $P_{o} / C$ \\
\hline \multirow[t]{2}{*}{ VII 6} & $\mathrm{R}$ & $0 \cdot 13$ & I 70 \\
\hline & $\mathbf{L}$ & 0.05 & 400 \\
\hline \multirow[t]{2}{*}{ VII 7} & $\mathbf{R}$ & $0 \cdot 19$ & 94 \\
\hline & $\mathrm{L}$ & 0.12 & I $4 \mathrm{I}$ \\
\hline \multirow[t]{2}{*}{ VII I I } & $\mathbf{R}$ & $0 \cdot 10$ & I 80 \\
\hline & $\mathrm{L}$ & $0 \cdot 06$ & 333 \\
\hline \multirow[t]{2}{*}{ VII I4 } & $\mathbf{R}$ & $0 \cdot 08$ & 425 \\
\hline & L & $0 \cdot 15$ & I 46 \\
\hline \multirow[t]{2}{*}{ VIII 18} & $\mathbf{R}$ & $0 \cdot 13$ & I 77 \\
\hline & $\mathbf{L}$ & $0 \cdot 15$ & 177 \\
\hline \multirow[t]{2}{*}{ VIII I9* } & $\mathbf{R}$ & $0 \cdot 15$ & II3 \\
\hline & $\mathbf{L}$ & $0 \cdot 15$ & II 3 \\
\hline
\end{tabular}

* This patient is not yet receiving treatment.

Twelve affected members of the family are myopic; this is usually simple myopia varying from about $\mathrm{I} \cdot 5$ to 4 dioptres, but in two it was as high as 10 dioptres. These patients are specially marked on the pedigree.

In all affected cases in this family both eyes were affected; there was no instance of $\stackrel{\infty}{+}$ uniocular involvement.

\section{Glinical progress of a case}

Examination of the eyes (or irides) externally in the first year or two of life can reveal whether an individual is affected or not. It can be stated with certainty at this age that those members of the family who do not have an iris typical of the condition will not develop 
glaucoma, and they are therefore excluded from further follow up. Those children who are affected are seen annually. When it is possible, applanation tonometry is performed. In childhood the visual acuity, intraocular pressure, and appearance of the optic disc are the parameters that are followed; in adult life the visual field is also assessed.

In childhood and early adult life the condition usually requires no treatment as the intraocular pressures are within normal limits for this condition. Of the six patients under 30 years, all have intraocular pressures below $22 \mathrm{~mm} . \mathrm{Hg}$ and are not receiving treatment. We have found over the years that treatment is not indicated until the fourth or fifth decade (Fig. 3). Thereafter treatment is required for the rest of the patients lives, as in ordinary cases of chronic simple glaucoma.

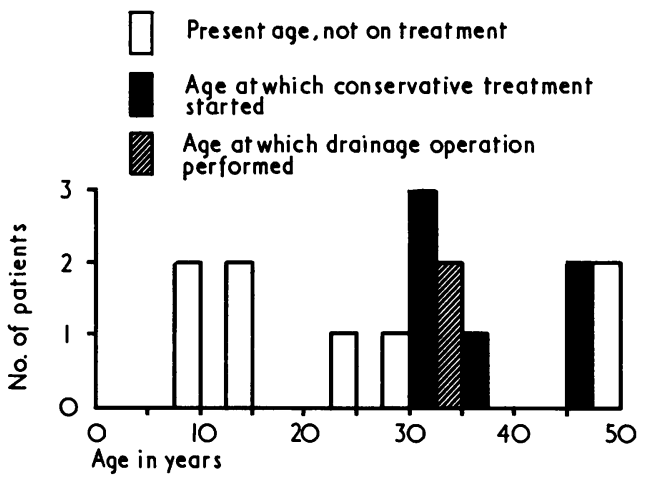

FIG. 3 Age at which treatment has been started in sixteen affected members of the family

The onset of glaucomatous cupping of the optic disc and loss of visual field-measured by central and peripheral fields-is the same as in any ordinary case of chronic simple glaucoma. The time of onset depends on the severity of the glaucomatous symptoms in each case. The progress of this familial glaucoma is similar to that of chronic simple glaucoma, but the visual loss starts at an earlier age. Despite treatment or drainage operations in the members of the family here studied, the condition progresses inexorably until the patient is fully registrable as blind.

\section{Treatment}

The routine therapy for chronic simple glaucoma is effective in reducing the intraocular pressures in most of our patients. The intraocular pressures, appearance of the optic discs, and state of the visual fields are observed and used as parameters to judge whether therapy is being effective or not. As with chronic simple glaucoma, the aim is to keep patients on conservative treatment as long as possible without loss of visual field or progression of cupping of the optic discs.

\section{Surgery}

In the early 1930s, A. Zorab performed aqueoplasty operations on four members of generation VI and one of generation VII. This is a filtration operation in which a silk wick is inserted through a corneoscleral keratome section, usually in the 12 o'clock position. The inner end of the wick just enters the anterior chamber at the angle, and the outer part lies under a conjunctival flap, forming a draining fistula (A. Zorab, 1912). These wicks have recently been seen on gonioscopy. These operations proved remarkably successful, the patients retaining a low intraocular pressures for many years. Unfortunately, patient VII 5 
has left the area and is not under our supervision, but the two patients who had this operation in both eyes (VI I and VI 5) are still alive and are observed from time to time. The former (VI I), who had aqueoplasties in each eye in I930-1935, retained good vision in each eye for some $2 \mathrm{I}$ years after the operation. After this time the pressures remained too high for safety and, despite further surgery on several occasions, the patient gradually lost vision. The other (VI 5), who had aqueoplasties in each eye in 1926 , retained good vision in one eye for 30 to 35 years, although the vision in the other was impaired, probably because of corneal vascularization. It is surprising that these drainage operations kept intraocular pressures within reasonable limits for so long.

\section{Discussion}

Of the hundred or more genealogies of primary glaucoma so far published, about one-third cover three generations or more. The majority of these cases are of so-called juvenile glaucoma. Whether this is a true entity is doubtful. François, Deweer, and van den Berghe (1950) stated that it was either late-developing congenital glaucoma or early-developing open-angle glaucoma. However this may be, it is a useful label for describing these cases which occur in early life, but which behave like the open-angle cases generally met with in the 50 to 80 -year age group.

Many cases of juvenile glaucoma are found only because an hereditary factor has been noted elsewhere in the family, and all other members are being screened. The converse is also true: if glaucoma is diagnosed in a young person it is liable to suggest the presence of an hereditary factor, and all other members have been screened with this in mind. This, and the greater ease of examining several generations when starting with a young patient, account for the preponderance of juvenile glaucoma in published cases. In this condition the hereditary factor is dominant, with a fairly high degree of penetrance. There are occasional cases where the dominance is irregular and a few where it appears to be recessive. This latter may be associated with consanguinity of the patients. This is in contrast to buphthalmos where the mode of inheritance is generally recessive.

The pedigree described by A. Zorab (1932) is repeated in Fig. 4; it consisted of one member of generation V, six of generation VI, and fourteen of generation VII. Their places on the present pedigree have been added in. Of these in the latter generation whom A. Zorab then said were not affected ( 13 members), nine are now affected by the condition. (It is likely that he did not realize at that time the significance of the iris colour.)

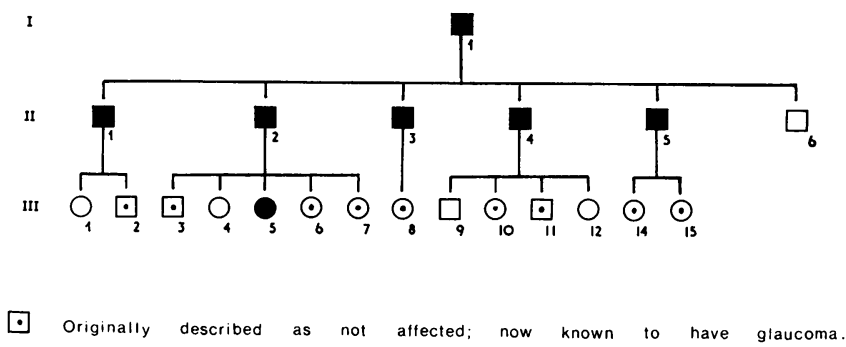

FIG. 4 Pedigree as described by A. Zorab (1932). Numbers indicate position on up-to-date pedigree (Fig. I)

The up-to-date pedigree demonstrates the autosomal dominant inheritance. The sex 
incidence of affected members is sixteen males ( 55 per cent.) and thirteen females (45 per cent.) (Table II). If one postulates that the affected members of the family are heterozygotes (and there is no evidence of consanguinity or marriage with another similarly affected family), then 50 per cent. of the offspring should be affected if the inheritance is autosomal dominant and if the gene shows complete penetrance. In this family 54 per cent. of offspring are affected, which is compatible with autosomal dominant inheritance with complete penetrance. This compares well with the findings of Weatherill and Hart (1969).

Table II Sex incidence in the family

\begin{tabular}{|c|c|c|c|c|}
\hline \multirow{2}{*}{$\begin{array}{l}\text { Total number of } \\
\text { affected members }\end{array}$} & \multicolumn{2}{|c|}{ Males } & \multicolumn{2}{|c|}{ Females } \\
\hline & No. & Per cent. & No. & Per cent. \\
\hline 29 & I 6 & 55 & I3 & 45 \\
\hline
\end{tabular}

The occurrence of glaucoma is sometimes associated with myopia. This is demonstrated in this family and the myopia also tends to show a dominant inheritance, being present in twelve of the affected members (48 per cent.). Crombie and Cullen (I964) found it in two-thirds of their cases; the association was also reported by McCulloch and MacRae (1950) and Weatherill and Hart (r969).

There are many reports of an association between iris colour and structure with glaucoma. Hambresin and Schepens (1946) reported a family affected by glaucoma; the irides of the affected members were always a dark chocolate brown colour. This was a positive family marker for glaucoma; unaffected members did not have this colour of iris. They also reported that, like our patients, iris vessels were easily visible, and that there were no normal surface markings.

Havener (1955) mentioned the presence of iris freckles in association with glaucoma. François (1950) described a family with glaucoma in which the affected members had greyish irides.

McCulloch and MacRae (1950) reported a family in which ten members had glaucoma, and nine of these had slate-grey irides, which were described as being thin and atrophic, with fine stromal trabeculae. Their unaffected subjects had brown irides; and they found open angles gonioscopically and no mesodermal tissue in the angles.

Weatherill and Hart ( 1969 ) described hypoplasia of the iris stroma in patients affected with familial glaucoma. The irides of the affected patients were either brown-the colour of dark bitter chocolate-or very dark slate grey. Gonioscopically, they found in some patients abnormal tissue in the angles covered with fine blood vessels, and in others anterior iris insertion, many fine iris processes, and fine vessels coursing between them. In contrast to our patients the manifestations of the condition in their family were variable; of their patients with abnormal irides and angles, some had glaucoma, and others did not; some had abnormal angles only; and some had glaucoma and abnormal angles, but normal irides.

\section{Summary}

A further report is given of a South Hampshire family with chronic glaucoma associated with developmental anomalies of iris and angle inherited as an autosomal dominant trait, 
affecting 29 of 62 members over nine generations. The peculiar colour and structure of the iris and the gonioscopic appearances are described. The progress of this disease as it affects an individual throughout life is described, and methods of conservative and surgical treatment are discussed.

We should like to thank Dr. J. Gloster who performed the tonographies, and also Mrs. C. M. Davies for secretarial help.

\section{References}

CROMbie, A. L., and cullen, J. F. (1964) Brit. F. Ophthal., 48, i 43

FRANÇois, J., DeweER, J. P., and VAN DEN BerGhe, J. (1950) Bull. Soc. belge Ophtal., no. 96, $66_{5}$

haMbresin, L., and schePens, c. (1946) Bull. Soc. franç. Ophtal., 59, 219

havener, w. H. (1955) Amer. F. Ophthal., 40, 828

MCGUlloch, C., and maGrae, D. (1950) Trans. Canad. ophthal. Soc., p. 79

WeAtherill, J. R., and hart, c. T. (1969) Brit. F. Ophthal., 53, 433

ZORAB, A. (1912) Ophthalmoscope, ro, 258

(1932) Trans. ophthal. Soc. U.K., 52, 446 